\title{
What are the affordances of information and communication technologies?
}

\author{
Grainne Conole ${ }^{\star}$ \& Martin Dyke \\ University of Southampton, UK
}

The paper examines the notion that Information and Communication Technologies (ICT) have affordances that epitomize the features of our late modern age (Giddens, 1991) and explores whether these affordances (Salomon, 1993, p. 51) can be used to facilitate particular approaches to educational practice. It argues that a clear articulation of these affordances would enable us to understand how these technologies can be most effectively used to support learning and teaching. We believe that any one affordance can be considered to have both positive and negative connotations and the paper draws on social and educational theory to provide an initial taxonomy of these affordances.

\section{Introduction}

There has been a rapid growth in online learning environments and associated tools to support learning and research. These include communication systems (email, discussion boards, synchronous chat), authoring and assessment tools, as well as integrated learning environments such as Blackboard and WebCT. Coupled with this, there is now a range of tools to facilitate information management including commercial products and subject-specific information gateways. Despite this, there is evidence of slow uptake in the use of these technologies within education (Jones, 1996). Britain and Liber (1999, p. 3) conclude that:

\begin{abstract}
amongst the factors that are slowing the uptake [is] ... the lack of a coherent framework within which to evaluate both the pedagogical benefits and the organizational changes required to effectively implement it.
\end{abstract}

Furthermore evaluation research to date shows that it is difficult to encourage authentic virtual learning or collaboration. Discussion board use, for example, often shows a pattern of peak use directly related to teacher intervention or responses to particular

\footnotetext{
ॠCorresponding author: School of Education, University of Southampton, Highfield, Southampton SO17 1BJ, UK. Email: G.C.Conole@soton.ac.uk
} 
'hot' topics. Collaborative group work needs to be set up carefully and orchestrated to achieve desired results and, despite this, may still end up as a rather stilted collaboration exercise not comparable with direct face-to-face equivalent group work (Jones, 1999). Integrated learning environments are still predominantly used as 'shells' for displaying web pages and rarely get beyond basic information dissemination and administration (Thomas \& Wyatt, 1999). With respect to information seeking and handling, the sheer volume available to learners/researchers is increasing exponentially, unmatched by the sophistication of the searching and handling tools (Lawrence \& Lee Giles, 1999). Information overload, coupled with confusion of where to look, is increasingly problematic and, despite a growth in the range of searching tools and portals, it is not evident that the right information is being dispatched to the right users in a timely and quality assured fashion (Conole, 2002).

Research into the use of ICT has increased significantly in the last decade and there is evidence that learning technology as a research discipline is now beginning to mature (Conole et al., 2003). However, research still tends to focus on particular case studies rather than the development of underpinning theories and approaches (Conole, 2004). Furthermore, little is understood about the 'affordances' of different technologies and, more specifically, how these properties might be exploited in particular learning and teaching contexts. We believe that a better understanding of the nature and properties of technologies will lead to a more systematic application of the use of ICT for learning and teaching. This paper attempts to draw out these inherent properties building on Gibson's concept of affordances (Gibson, 1979) and Beck's understanding of risk (Beck, 1992).

The paper outlines the current developments in ICT research and the associated perspectives and views. The notion of affordances is described, as well as ways in which it might be used to develop a better understanding of the properties of different technologies. We argue that there is a need to explore a theoretical basis for the use of ICTs and present a conceptual framework as an attempt to further explore the notions of affordances in this respect. The research methodology used and the social theory on which the paper draws, are then described. The paper concludes with suggestions for further research.

\section{Current perspectives on technologies-myths and realities}

The best example of the increased use and importance of ICT is the now ubiquitous use of the PC as a work tool and the replacement of many traditional work modes of communication, such as memos, with online communication via email. There has been a commensurate growth in the use of technology to support learning, fuelled by the increased use of all-in-one software such as virtual learning environments. There has also been a growth in the amount and variety of resources to support learning and research, through specialized gateways and portals, and niche resource providers. The types of software tools, hardware systems and online environments have also increased in variety and complexity, with tools now available to support everything from research publication management to online assessment and monitoring. 
These developments have been met by a spectrum of views, ranging from wholesale acceptance and calls for pedagogical re-engineering and revolutionizing educational systems, through to significant dissent and cynicism about the use and value of these new tools. In addition, there are growing concerns about the unintended consequences of these changes, such as potential job losses, fears of increased surveillance methods and associated ethical questions (Bonk, 2001; Borgman, 2001; Schuck, 2001; Land \& Bayne, 2001; McKenna, 2002). The hegemony within this continuum of views has ebbed and flowed over the last decade, as outputs from research have accumulated to support different perspectives, and as the population in general becomes more e-literate and comfortable with using the technologies. The variety of ways in which technologies can be used to support learning and teaching, and the enabling tools and resources available to support this process, have increased significantly. However, evidence suggests that practitioners are still unclear about how to use technology appropriately, and its application is often based on common sense rather then being theoretically informed by pedagogical theory (Conole et al., 2004). One reason for the lack of application of models and theories by e-learning practitioners may be that, as academics outside the field of education, they find the diverse array of theoretical perspectives alien and overwhelming (McNaught, 2003). One important stakeholder in this respect are learning technologists, who work with academics and teaching practitioners to exploit new technologies. These 'new professionals' frequently have a very good grasp of current theories and models for e-learning and have the skills to support those academic staff who are less familiar with pedagogical theory.

\section{A taxonomy of ICT affordances}

This section defines the notion of affordances and outlines a taxonomy of ICT affordances with a description of each. Salomon describes Gibson's concept of affordances as follows.
'Affordance' refers to the perceived and actual properties of a thing, primarily those func- tional properties that determine just how the thing could possibly be used. (Salomon, 1993, p. 51)

Salomon goes on to describe how Norman has developed this concept and, in particular, the notion that the affordances of many objects (such as microwaves, car instruments, etc.) often restrict their accessibility to users, arguing that better design of artefacts would make it easier to accomplish certain functions. We argue that this could be developed further and, when applied to current ICT applications, can have both positive and negative impacts on the users. Pea builds on this in terms of the concept of 'Person Plus', which is the concept of cognition being distributed between the person and their environment, and associated artefacts (Pea, 1998).

Application of the concept of affordances centres around three main research questions:

- How might the affordances of technologies be articulated?

- Can these be developed into a taxonomy for ICT? 
- How might a critical knowledge and understanding of such affordances be used to support learning and teaching?

Firstly, relevant current social theory and critique were analysed to establish the key features of modernity and, where relevant, to map this specifically to ICT. In particular, we have drawn on the work of Giddens (1990, 1991) on late modernity, Castells' work on the nature of the networked society (Castells, 1996), and Engestrom's critique of activity theory (Engestrom et al., 1999). Secondly, the literature on the current use of technologies was analysed. From this analysis a list of the potential themes and commonalities was drawn up and distilled into a taxonomy of ICT affordances, which is outlined below.

\section{Accessibility}

The range of ICT now available offers relatively easy access to vast amounts of information through a variety of different mechanisms. Online access is possible via gateways, portals and websites as well as via knowledge networks and shared communities of users. However, the corollary of this is that there has been an exponential increase in the amount of information and the means of accessing it, which leads to issues of information overload, quality assurance and the need for more critical evaluation. This will require a change in the users' learning and information analysing skills. The challenge is not in accessing material, but rather in knowing how to use what is available. Perhaps the balance has shifted from 'searching' to 'selecting'.

\section{Speed of change}

An element of the late-modern perspective adopted here, is the information society discourse, where abundant and rapidly changing information is mediated through extensive communication technologies (Castells, 1996). Giddens acknowledges the importance of information in guiding decision-making:

Social reflexivity refers to a world increasingly constituted by information rather than pregiven modes of conduct. It is how we live after the retreat of tradition and nature, because we have to take so many forward orientated decisions. In that sense, we live in a much more reflexive way than previous generations have done. (Giddens, 1999a, p. 15)

Continuous reassessment of experiences, and also of the information which is part of these experiences, is therefore central to living with the rapid change of late-modernity. Earlier forms of modernity could more frequently use custom and tradition to guide action. The immediacy of access to rapidly changing information or events is a core feature of new technologies, enabling unprecedented speed of access to materials and world events as they happen. However, this speed can also raise issues about quality, lack of authority of sources and lack of reflection. The speed of change may also mitigate against reflective and critical thought, fostering surface approaches to learning. Reflection as an affordance will be considered below. The issue here is that the speed of change in a world full of conflicting and changing information, is a challenge for the educational use of the new technologies. In other words, how can it 
be used to enable students to navigate their way through the myriad of changing information and make more informed decisions?

\section{Diversity}

ICT offers access to a vast range of diverse and different experiences that can inform learning such as overseas web sites, access to subject experts, or use of simulations to replicate complex behaviour. Exposure to the experience of others is a key ingredient to effective learning and a potential affordance of ICT.

The work of Boud (1993) and his colleagues defines learning as a holistic activity that needs to connect with people's life experiences. Learning is recognized as constructed in a social, economic and cultural context. Boud emphasized the value of learning from the experience of others, of sharing experience and exposing ideas to the critical gaze of the 'other'. He argued:

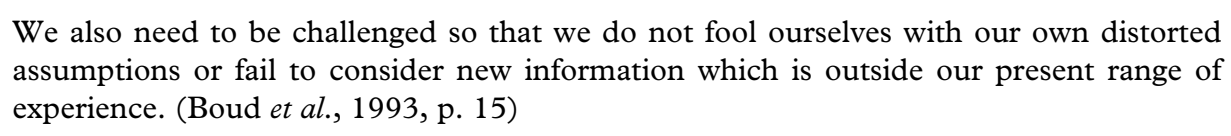

We also need to be challenged so that we do not fool ourselves with our own distorted assumptions or fail to consider new information which is outside our present range of experience. (Boud et al., 1993, p. 15)

Information technologies provide a means by which people can be exposed to experiences very different to their own and extend their experience beyond their own communities. Experience of the 'other' through technology raises issues around authenticity and power in the 'virtual reality' that can be accessed. For example, there may be disjuncture between the mediated 'reported' experience and the reality of lived experience. It raises questions about how one distinguishes between what is real and what is rendered real via the technology.

\section{Communication and collaboration}

The communication and collaborative abilities of technology present another key affordance that offers the potential for learning enriched by engagement with the 'other'. New technologies have opened up the possibility of new forms of dialogue and communication. ICT offers the potential to develop new forms of online communities and new means of communicating and sharing information, from signing up to particular mailing lists through to involvement in specialized discussion forums and chat rooms. The engagement with difference and the acknowledgement of diversity through communicative discourse connects with critical social theory and the Habermasian idea of ideal speech situations (Habermas, 1970). The importance to learning is documented in Vygotsky's approaches to learning (Engestrom et al., 1999). This also aligns well with Wenger's notion of Communities of Practice (Wenger, 1998). However, this can lead to issues in terms of individuals being 'spread too thinly' across communities, as well as issues of lack of identity and peripheral engagement. Bauman presents a pessimistic view of modernity where:

Unable to stop treading on each others toes in the mega-community, we have stepped into our separate houses and closed the door, and then stepped into our separate rooms and closed the door. (Bauman, 1995, p. 45) 
But this can also raise questions about the communication and literacy skills of end users. Issues and concerns about the e-literacy of both staff and students are currently being debated through a series of symposia organized by the Joint Information Systems Committee JISC. ${ }^{1}$

\section{Reflection}

Asynchronous technologies (in particular) offer the potential for encouraging reflection and critique, with users engaging in discussions over a longer time frame than is possible in face-to-face discussions. In addition, users are able to access and build on archived material available from earlier discussion. Asynchronous technologies have been used successfully, particularly in the use of discussion forums to support learning, but are also being used increasingly to support the research and teaching activities of academic staff. Clearly, there is nothing inherent about ICT that nurtures reflection - the key is how it is used. ICT has the potential to enable reflection and criticality to be enhanced. It presents new opportunities for knowledge claims to be considered and subjected to the critical gaze of much wider and more diverse communities of practice. Recently we have begun to look at this in more detail and have developed a map of learning theories against specific learning characteristics such as reflection and collaboration (Conole et al., 2004). We are now using this as a basis to develop a learning design toolkit which aims to provide a more explicit and pedagogically grounded use of tools and resources, as part of the JISC/NSF-funded DialogPlus project. $^{2}$

There is, equally, a risk that the speed and pace of information change outlined above militates against reflection. It leaves no space for contemplation and considered judgement, and promotes a more pragmatic, reflexive immediate response to new information, as it is pixilated across our screens. This can be said to be particularly true of email, where nowadays users are bombarded with so much information that there is a tendency to skim read and adopt a surface approach in terms of reacting to responses and requests (Gibbs, 1992). This view is presented in Lash's 'Critique of Information' (Lash, 2002). Perhaps new forms of reflection and critique will emerge in response to more transitory and digital text. Though, as Bauman's (2000) analogy of 'liquid modernity' suggests, the shape and form might change. The issue is whether the essential ingredients of modernity, or in our case, learning through technology, remain the same? At a political level, there is evidence that globalization has nurtured, rather than stifled, critical reflection and resistance (Klein, 2001; Stiglitz, 2002; Monbiot, 2003). The challenge, as Laurillard (2002) notes, is how we can use ICT to transform information into 'knowledge', a process which has parallels in Dewey's (1933) advocacy of critical reflection upon experience to create knowledge.

\section{Multimodal and non-linear}

The non-linearity of the web (epitomized by hypertext and the use of powerful search engines) leads to the potential for different routes through, and forms of, learning. 
ICT enables the learner to move beyond linear pathways of learning, characteristic of, but not exclusive to, behaviourist approaches, and to adopt more individualized strategies and pathways. Dewey's (1933) pragmatic approach to experiential learning is more characteristic of non-linear learning achievable with ICT than that of the more prescriptive learning cycle of Kolb (1984). Another affordance of ICT is the potential for multi-modal and non-linear approaches to learning. Yet much current computerbased training material still appears to follow a linear, assembly line, mode of learning. Many 'e-learning' packages are built on behaviourist principles of atomized experiences that need to be completed in a specified order before the individual is positively reinforced and permitted to move on-a form of electronic page-turning. The issue may be whether there is a stark contrast between the method of learning promoted with many computer-based tutorial packages, and the experimental and pragmatic way in which most people acquire for themselves skills in ICT. Multimodal and non-linear learning modes are perhaps an under-utilized affordance of ICT.

\section{Risk, fragility and uncertainty}

Anthony Giddens argues that the concept of risk is central to our understanding of contemporary modernity. Giddens defines risk as being different from dangers or hazards in that they are essentially related to the impact of humanity on the world and relate to the consequences of our actions in our world. Risk, therefore, is different from fate or 'natural' disasters, it relates to choices people make about avoiding risks or taking them.

Manufactured risk means human risk environments, or human environments of uncertainty, created by the very changes I discussed in the last lecture, created partly by the advance of science and technology. (Giddens, 1999b, p. 5)

Connected to risk are the unintended consequences of actions (Giddens, 1990, 1999a). These concepts are particularly pertinent to the context of information technologies, where history shows that there have been major unintended consequences, i.e. the technologies have not necessarily been taken up or used in the ways originally intended. Furthermore, another aspect of the rapidly changing nature of ICT is that there is an intrinsic level of fragility in digital technologies and networks. These complex systems are vulnerable to abuses, to disruption from viruses and SPAM, or simply to the servers 'being down'. The increased use of technologies by different groups of users often gives rise to unintended consequences. For example, the increase in the volume of information available on the web has led to new forms of plagiarism. Ubiquitous use of email has resulted in increasing commercial exploitation and unwelcome mail. There are risks and levels of uncertainty associated with a dependence and reliance on the instantaneous provision of information and communication. The intensification of work (Pollert, 1991) and need for immediacy associated with the 'flexibility' presented by information and communication technologies, can result in levels of dependence whereby an individual's success or failure in meeting commitments hangs by a tenuous digital thread. 


\section{Immediacy}

The speed with which information can be exchanged via the web and email has led to a shift in user expectations in terms of response times to requests from other users. This, in turn, has led to a consequential intensification of working patterns, with users being increasingly required to respond almost immediately to requests which, in the past, would have been dealt with over longer timeframes.

\section{Monopolization}

Convergence and divergence of different technologies is increasingly important, leading to issues associated with scalability and globalization and the underpinning standards needed to support interoperability. A current focus is also on a critique of convergence verses standardization across the technical, pedagogical, human and organizational aspects. There is a tension between the benefits of diversification and sharing of developments, a central ethos of the open source community with that of monopolization and co-modification, such as the dominance of particular software products to support office applications.

\section{Surveillance}

New technologies present new Foucauldian means by which those with power can extend their gaze and secure greater knowledge and control over others (Foucault, 1979). There is increasing concern about potential infringements on individuals which the infiltration of technological applications make possible. Land and Bayne (2001), for example, have critiqued the increased default inclusion of monitoring tools within virtual learning environments that mean teachers have the power to monitor student activities more closely than ever before. McKenna (2002) critiques the use of the blind copying function in email being used as a potential power tool unknown to recipients of the main email. Similar concerns are being voiced about many of the new 'smart' devices and personal tags which are being included in commercial products that enable providers to target and personalize products more accurately. There are concerns about how these tracking devices might be used for other purposes (such as surveillance) or by other agents.

\section{Application of the taxonomy}

The proposed taxonomy of ICT affordances can then be used in a number of ways:

- To carry out further analysis, critique and development of the taxonomy framework against relevant theory and practical use.

- To establish a clearer understanding of the affordances which should help to inform practitioners in their use of particular technologies to achieve particular goals. 
- To identify potential limitations and inappropriate uses of the technologies.

- To act as a discussion point for critique and further refinement.

- To offer a checklist to help practitioners understand costs and benefits of different technologies.

- To use as a mechanism for staff development and improving practice - for example, by providing a checklist of potential benefits and draw backs of different technologies which can be used to inform choice and the ways that practitioners might choose to use them.

Many of the affordances outlined above are known intuitively, but the development of an explicit taxonomy provides a basis for discussion, critique, and further refinement. This may involve questions such as:

- Are these the only affordances?

- Does their articulation make the benefits and potential drawbacks of technologies more explicit?

- Can particular affordances be mapped to particular types of technologies?

We believe that the taxonomy will be useful as a checklist for practitioners, to help them make informed decisions about the use of different technologies. It may also, in part, help to make them more aware of the properties of different tools and resources, and use this as part of their decision making process in developing learning activities and teaching plans. We are also considering how this might be used as part of a wider learning design process. This might involve integrating the use of technologies with other teaching methods, tools and resources, through the development of a learning design toolkit, which aims to enable practitioners to map particular pedagogical approaches to their learning design (Conole et al., 2004).

\section{Discussion}

This paper has considered whether application of the concept of affordances might enable better use and understanding of technologies and their application to learning and teaching. However, this approach leaves a number of unresolved questions.

- How valuable is the concept of affordances and does its application provide any really new insight into the inherent properties of technologies?

- How valid is the methodological approach suggested?

- What other approaches might be taken?

- The approach suggested reflects a particular interpretation of social theory. Is this a limitation and might a broader analysis of other social theories yield new insights?

- Practitioners are still exploring the potential of new technologies, and the current uses of technologies often do not take full advantage of the medium. Therefore, how can practice take full advantage of the affordances of ICT?

- Does understanding of the affordances actually get us closer to improvement in practice and is this a useful framework? 
A fundamental issue is the level of granularity at which this taxonomy might be appropriate; is the taxonomy useful as a philosophical critique of the inherent affordances of ICT at a general level or can it be used more explicitly in terms of actually mapping to particular uses. Our work in the development of the learning design toolkit as part of the DialogPlus project is exploring this issue. ${ }^{2}$ To address these questions we intend to examine the issues further and discuss these ideas with researchers. In addition, we plan to test out the use of the taxonomy in the ways outlined above with practitioners. These activities should help practitioners to refine and develop the taxonomy and to give a clearer insight into its potential use. We believe that this approach is timely given that there has been little done in the application of the concept of affordances to date in learning technology and given the increased diversity and potential applications of learning technologies.

By making the affordances explicit in the form of a taxonomy it will be possible for practitioners to make more informed choices about the ways in which different technologies can be used. As a next stage we plan to assign different affordances to specific technologies to provide a mapping of the potential applications of different technologies. This we hope will provide a mechanism for identifying the strengths and weaknesses of different technologies and the ways they can be used. For example a mapping of the communication and reflection affordances to asynchronous and synchronous communication mechanisms will reveal that both have strengths in terms of supporting communication, but that the latter may also have greater potential to nurture critical and reflective thinking.

\section{Notes}

1. www.jisc.ac.uk

2. www.dialogplus.org

\section{References}

Bauman, Z. (2000) Liquid modernity (Cambridge, Polity).

Bauman, Z. (1995) Life in fragments (Cambridge, Polity).

Beck, (1992) Risk society towards a new modernity (London, Sage).

Bonk, C. J. (2001) Online teaching in an online world, Indiana University, available online at: http:// www.courseshare.com/reports.php.

Borgman, C. L. (2001) Digital libraries and virtual universities, in: T. D. Senta \& T. Tschang (Eds) Access to knowledge: new information technologies and the emergence of the virtual university (Paris, International Association of Universities Press), 207-240.

Boud, D., Cohen, R. \& Walker, D. (1993) Using experience for learning (Buckingham, Society for Research in Higher education/ Open University Press).

Britain, S. \& Liber, O (1999) A framework for pedagogical evaluation of virtual learning environments, FISC Technology Applications Programme, Report No. 41. available online at: http:// www.jisc.ac.uk/index.cfm?name=project_pedagogical_vle

Castells, E., (1996) The information age: economy, society and culture Vol. I. The rise of the network society (Oxford, Blackwell).

Conole, G. (2002) Systematising learning and research information, fournal of Interactive Media in Education, 7, available online at: http://www-jime.open.ac.uk/2002/7/ 
Conole, G., Ingraham, B. \& Cook, J. (2003) Learning technology as a community of practice? In Proceedings of 10th International Conference for the Association for Learning Technology (ALT-C 2003), 11-13 September, Sheffield.

Conole, G. (2004) Research questions and methodological issues, in: J. Seale (Ed.) Learning technology in transition: from individual enthusiasm to institutional implementation (Lisse, Swets and Zeitlinger).

Conole, G., Dyke, M., Oliver, M. \& Seale, J. (2004) Mapping pedagogy and tools for effective learning design, Computers and Education, 43, 17-33.

Dewey, J. (1933) How do we think? In: J. Boyston (Ed.) fohn Dewey the later works, 1925-1953 (Vol. 8) (Carbondale, IL, Southern Illinois University Press).

Engestrom, Y., Miettinen, R. et al. (Eds) (1999) Perspectives on activity theory. Learning in doing: social, cognitive and computational perspectives (Cambridge, Cambridge University Press).

Foucault, M. (1979) Discipline and punish: the birth of the prison (Harmondsworth, Penguin).

Gibbs, G. (1992) Improving the quality of student learning (Bristol, Technical \& Educational Services).

Gibson, J. J. (1979) The ecological approach to visual perception (Boston, MA, Houghton Miflin).

Giddens, A. (1990) The consequences of modernity (Cambridge, Polity Press).

Giddens, A. (1991) Modernity and self identity (Cambridge, Polity Press).

Giddens, A. (1999a) Runaway world: how globalisation is reshaping our lives (London, Profile).

Giddens, A. (1999b) The Reith Lectures revisited. Directors Lecture 2. London School of Economics, 17 November 1999. Available online at: http://www.lse.ac.uk/Giddens/pdf/17-Nov-99.PDF

Habermas, J. (1970) Towards a theory of communicative competence, in: G. Dreitzel (Ed.) Recent sociology: patterns of commmunicative behaviour (New York, Macmillan).

Jones, A. (1995) Constructivist learning theories and IT, in: N. Heap, R. Thomas, G. Eionon, R. Mason \& H. Mackay (Eds) Information technology and society (London, Sage), 249-265.

Jones, C. (1999) From the sage on the stage to what exactly? Description and the place of the moderator in co-operative and collaborative learning, $A L T-\mathcal{F}, 7(2), 27-36$.

Kimball, L. (1998) Managing distance learning-new challenges for faculty, in: R. Hazemi, S. Hailes \& S. Wilbur (Eds) The digital university (Berlin, Springer), 25-38.

Klein, N. (2001) No logo: no space, no choice, no jobs (London, Flamingo).

Kolb, D. (1984) Experiential learning (Upper Saddle River, NJ, Prentice-Hall).

Land, R. \& Bayne, S. (2001) Screen or monitor? Issues of surveillance and disciplinary power, in: 'Online Learning Environments', 9th Improving student learning symposium, improving student learning using learning technologies, 9-11 September, Heriot Watt University.

Lash, S. (2002) Critique of information (London, Sage).

Laurillard, D. (2002) Rethinking university teaching - a framework for the effective use of educational technology (2nd edn) (London, Routledge).

Lawrence, S. \& Lee Giles, C. (1999) Accessibility of information on the web, Nature, 400, 107109.

MacKenzie, D. \& Wajcman, J. (Eds) (1985) The social shaping of technology (Buckingham, Open University Press).

McKenna, C. (2002) What do we mean by electronic literacy? in: Proceedings of the Improving Student Learning Using Learning Technology Conference, Heriot Watt, 79-88.

McNaught, C. (2003) Identifying the complexity of factors in the sharing and reuse of resources, in: A. Littlejohn (Ed.) Reusing online resources - a sustainable approach to e-learning (London, Kogan Page).

Monbiot, G. (2003) The age of consent: a manifesto for a new world order (London, Flamingo).

Pea, R. (1998) Practices of distrbuted intelligence and designs for education, in: G. Salomon (Ed.) Distributed cognition (Cambridge, Cambridge University Press).

Pollert, A. (1991) Farewell to flexibiltiy (London, Basil Blackwell).

Salomon, G. (Ed.) (1993) Distributed cognitions-psychological and educational considerations (Cambridge, Cambridge University Press). 
Schuck, S. (2001) Walking the electronic tightrope: questions surrounding infusion of IT into education subjects, Proceedings of the Improving student learning conference, Heriott Watt.

Stiglitz, J. (2002) Globalisation and its discontents (London, Allen Lane).

Thomas, G. \& Wyatt, S. (1999) Shaping cyberspace-interpreting and transforming the Internet, Research Policy, 28(6), 681-698.

Wenger, E. (1998) Communities of practice-learning, meaning and identity (Cambridge, Cambridge University Press). 